\title{
Decision threshold associated with multiple measurements. Application to the synthesis of the environment monitoring results
}

\author{
A. VIVIER ${ }^{1}$, G. MANIFICAT ${ }^{2}$, J-L.PICOLO ${ }^{3}$, S. FLEURY $^{3}$, M. MOKILI $^{4}$, X. GUO $^{5}$
}

(Manuscript received 29 June 2011, accepted 24 October 2011)

ABSTRACT When the sample activity is measured for various reasons several times, then with each measurement can be associated an individual decision threshold and limit of detection. Each measurement can be analyzed through its own decision threshold. The whole measurements can sometimes present contradictory results, some measurements being lower than the decision threshold and other higher. The problem then arises to build a decision threshold and a detection limit taking into account all the individual results, and to decide if the radioactivity is finally detected or not. It is interesting to note that it is possible sometimes that the decision threshold taking account all results makes it possible to decide that the radioactivity is present whereas the totality of the individual results are negative in terms of individual decision threshold. The purpose of this article is to show how these thresholds and these coherent limits cumulated can be determined in way according to the experimental conditions. In a general way a rigorous method of cumulating makes it possible to systematically decrease the decision threshold and limit of detection in terms of activity. This approach has interesting applications in gamma spectrometry with multi-emitters, discharge or periodical environmental measurements. On the basis of measurements realized by the IRSN within the framework of the national monitoring of the environment, we will see the potential impact of these methods on the final assessments.

Keywords: Decision threshold / detection limits / multiple measurements

RÉSUMÉ Seuil de décision associé à des mesures multiples. Application à la synthèse des résultats de surveillance de l'environnement.

Quand l'activité d'un échantillon est, pour des raisons diverses, mesurée plusieurs fois, à chaque mesure peuvent être associés un seuil de décision et une limite de détection qui lui sont propres. Chaque mesure peut être analysée au travers de son propre seuil de décision. L'ensemble des mesures peut parfois présenter des

CEA, Institut national des sciences et techniques nucléaires, Centre de Saclay, 91191 Gif-sur-Yvette Cedex, France.

IRSN, Direction de l'environnement et de l'intervention, Service d'étude et de surveillance de la radioactivité dans l'environnement, BP 40035, 78116 Le Vésinet Cedex, France.

3 IRSN, Direction de l'environnement et de l'intervention, Service de traitement des échantillons et de métrologie pour l'environnement, BP 40035, 78116 Le Vésinet Cedex, France.

4 Laboratoire SUBATECH - UMR 6457, École des Mines de Nantes, IN2P3/CNRS, Université de Nantes, 4 rue Alfred Kastler, La Chantrerie, BP 20722, 44307 Nantes Cedex 03, France.

5 ORTEC-AMETEK Inc, 801 S. Illinois Ave., Oak Ridge, TN 37830, USA. 


\begin{abstract}
résultats contradictoires, certaines mesures étant inférieures au seuil de décision et les autres supérieures. Le problème se pose alors de construire un seuil de décision et une limite de détection prenant en compte tous les résultats individuels, et de décider si la radioactivité est finalement détectée ou non. Il est intéressant de noter qu'il est possible parfois que le seuil de décision cumulé sur l'ensemble des résultats permette de décider que la radioactivité est présente alors que la totalité des résultats individuels sont négatifs au sens du seuil de décision associé à chaque mesure. L'objectif de cet article est de montrer comment se déterminent ces seuils et ces limites cumulés de façon cohérente en fonction des conditions expérimentales. De façon générale, une méthode de cumul rigoureuse permet de diminuer systématiquement les seuils de décision et les limites de détection en termes d'activité. Cette approche trouve des applications intéressantes en spectrométrie gamma sur des émetteurs multi-gamma, sur des rejets d'effluents ou sur des mesures périodiques et environnementales. En partant des mesures réalisées par l'IRSN dans le cadre de la surveillance nationale de l'environnement, nous verrons l'impact potentiel de ces méthodes sur les bilans finaux.
\end{abstract}

\title{
1. Introduction
}

The experimental situations where it is possible to cumulate multiple measurements are varied but can be distributed according to three possible general outlines:

- Case No. 1 (repeatability): iteration of measurements on the same sample under identical measurements conditions, except possibly the duration of counting;

- Case No. 2 (simple reproducibility): reproduction of measurements on the same sample under conditions of different measurements: efficiencies, systems of measurement...

- Case No. 3 (widened reproducibility): multiple measurements of different samples but obtained starting from a single measurand to be defined.

In all cases the objective is to consider situations where the accumulation of the obtained values has a sense, anyway this accumulation corresponds to the sum of individual measurements, or their algebraic or weighted average, or any other statistics resulting from the whole of the results. Let us consider for example the current situation of a measurement by gamma spectrometry of a sample likely to contain a multi-emitter gamma radionuclide. The taking into account of all the $n$ regions of interest (ROI) of this radionuclide on the experimental spectrum falls under the case No. 2. Indeed each ROI can be considered as a specific nuclear counter of a specific photons energy emitted by this radionuclide. Each one of these "counters" can be used to estimate the activity of this radionuclide. But the energy photons, the intensities of emission and the efficiencies are different from one ROI to another, thus answering the criterion of reproducibility. Thus is obtained $n$ estimations $\hat{\mathcal{A}}_{n}$ of the same true activity $\tilde{\mathcal{A}}_{n}$ under reproducibility conditions (case No. 2). These estimations, thus measured, have vocation to be of 
the same order of magnitude, but not their uncertainties nor their decisions thresholds.

One can show that in such a situation the best estimation of the true value consists in taking the average of the $n$ measured activities weighted by precision ${ }^{6}$. This step corresponds to the taking into account of all the accessible information in the spectrum concerning this radionuclide, step called here in a generic way "accumulation", and not with the taking into account only of the best individual estimation among the $n$ obtained. The best individual estimation corresponds in general to the estimation having smallest uncertainty, here in an equivalent way to the "more filled" peak. One can then show that the estimation by accumulation, here the weighted average, is always better than best individual estimations. This result is intuitively understood insofar as each measurement integrated into the accumulation brings a quantity of additional information, in proportion to its precision, which can only more or less improve final information. It is obviously all the interest to cumulate the whole of information available when possible.

In gamma spectrometry the use of the weighted average with all peaks of the same radionuclide does not pose any problem in so far as these peaks "are sufficiently filled" and those peaks are interference-free. Less prosaically the calculation of the weighted average does not pose any problem to the users when all the estimations are higher than their respective decision thresholds, meaning here that each measurement is considered to be significant of a proven presence of the radionuclide in the sample. Problems appear when all or part of the $n$ measurements are lower than their respective decision thresholds. Indeed when a measurement is lower than its decision threshold, one decide that the effect is not detected and declare " $<$ LD", that is to say that the true value, in case of the sample would be radioactive, is at least lower than the detection limit associated to the considered ROI.

Thus when $m$ measurements on $n$ are in this case there, several questions appear:

- Question 1: is it necessary to integrate these $m$ nonsignificant measurements into the accumulation?

- Question 2: if "yes", in which manner to take into account information like "<LD"?

- Question 3: if "not", neglecting such result cannot give the risk of biasing final result?

${ }^{6}$ Precision can be defined like the inverse of the square of uncertainty. Thus to a small uncertainty corresponds a high degree of precision. It is also the quantity of information in the sense of Fischer. 
- Question 4: always in this last case what can be done if all measurements are lower than their respective decision threshold?

- Question 5: in all cases what is the decision threshold and the detection limit corresponding to the final weighted average?

- Question 6: can one, in a way or another, use the $n$ individual decision thresholds to determine the decision threshold on the result obtained by accumulation?

Various methods exist in the litterature to try to exploit nonsignificant measurements (Fiévet and Della Vedova, 2010; Helsel, 2005). These methods can be rather heavy to implement and vary according to the proportion $\mathrm{m} / \mathrm{n}$. We will not approach these methods here but they are only stopgap without rigorous basis. Apart from this point, the objective of this article is to answer these various questions, and to show the interest to cumulate multiple measurements correctly when that is possible. We will see that this interest increases when the number of available measurements increases. In some experimental situations, like the periodic or continuous follow-up of the radioactivity monitoring in the environment, where measurements are often close to the decision thresholds, the number of measurements is indeed very high and the impact of these methods on the relevance of the end result can often be spectacular, at the point to even make doubt legitimacy of these methods.

One of the most important parts of the answer, justified later, is that actually one must not care to know, in the objective to analyse a cumulated result, if individual measurements are lower or not than their own decision threshold. In fact take care of such individual information to take a final decision on cumulated results is not only useless but raises insurmountable difficulties. Some of the questions which we have just mentioned, for legitimate that they can appear, should not be posed, question 2 particularly.

\section{Determination of the decision threshold cumulated in the case of counting repetition}

\subsection{Description of the repeatability process and analyze of individual results}

On the basis of a simple situation, corresponding to the case No. 1, it is possible to lay down without difficulties the principal rules which one will find in all the cases of figure. Moreover this simple situation of accumulation is already implicitly at work when one takes a single measurement of activity starting from a single background counting and a single sample raw counting. Thus a ten seconds single 
measurement is nothing else than ten one second measurements accumulation (integration).

One considers a series of ten measurements of the same sample under repeatability conditions: same measurement device, same distance sourcedetector, same background condition, same counting duration. For each individual measurement " $i$ " one can distinguish several phases in the operation from measurement to final analysis:

\section{Phase 1: construction of the decision-making aid tool}

- Background counting for a duration $T_{o}$ identical to the duration of sample counting noted $T_{s}$ : the result is noted $B k G_{i}$.

- Determination of the decision threshold in terms of net counting value following the formula $L c_{N e t i}=k_{1-\alpha} \sqrt{2\left(B k G_{i}+1\right)}$ (1).

- Determination of the detection limit in terms of net counting value following the formula $L D_{\text {Neti }}=k_{1-\beta}^{2}+2 L c_{\text {Neti }}(2)$, corresponding to the case of alpha and beta identical risks.

In equation (1), 1 extra count appears naturally in a Bayesian determination of decision threshold, and fortunately prevent from being zero in case of zero background (Vivier and Aupiais, 2007).

\section{Phase 2: sample measurement}

- Gross count sample: the result is noted $\operatorname{Gross}_{i}$.

- Determination of net counting value by correction of background noise Net $_{i}=$ Gross $_{i}-B k G_{i}$.

\section{Phase 3: analysis of the result}

- Decision threshold Test : Net ${ }_{i}>L c_{\text {Neti }}$ ?

- If "yes" the effect is considered detected. Estimation of true average net counting value and associated uncertainty $\hat{\mu}_{N e t}=N e t_{i} \pm k \sqrt{N e t_{i}+2 B k G_{i}}$ (typically $\mathrm{k}=1,2$, or 3 ).

- If "not" the effect is regarded as not detected. Final expression of the result:

$$
"<L D_{N e t} " \Leftrightarrow 0<\mu_{N e t}<L D .
$$

Note: insofar as counting duration $T_{0}$ and $T_{s}$ are identical and reasonning on counting values and not on counting rates, these time variables do not intervene explicitly in the calculation of the thresholds and limits. In the opposite case, 
if $T_{0} \neq T_{s}$, one would have then $L c_{\text {Neti }}=k_{1-\alpha} \sqrt{\left(1+\frac{1}{r}\right) \cdot \frac{B k G_{i}+1}{r}}$ with $r=\frac{T_{0}}{T_{s}}$ (Vivier
and Aupiais, 2007).

Numerical example:

TABLE I

Individual analyzes of 10 counting values of the same sample (alpha risk error at $2.5 \%$ ).

\begin{tabular}{ccccccccc}
\hline & Phase 1 & \multicolumn{4}{c}{ Phase 2 } & \multicolumn{3}{c}{ Phase 3 } \\
\hline$B k G_{i}$ & $L c_{\text {Neti }}$ & $L D_{\text {Neti }}$ & Gross $_{i}$ & Net $_{i}$ & $\begin{array}{c}\text { Net }> \\
\text { Lc? }\end{array}$ & Result & $\begin{array}{c}\text { Uncertainty } \\
(\mathrm{k}=2)\end{array}$ & $\begin{array}{c}\text { Relative } \\
\text { uncertainty }\end{array}$
\end{tabular}

\begin{tabular}{|cccccccccc|}
\hline meas. 1 & 100 & 28 & 59 & 143 & 43 & yes & 43 & 31 & $73 \%$ \\
\hline meas. 2 & 96 & 27 & 58 & 148 & 52 & yes & 52 & 31 & $60 \%$ \\
\hline meas. 3 & 113 & 29 & 63 & 130 & 17 & no & $<$ LD & $/$ & $/$ \\
\hline meas. 4 & 117 & 30 & 64 & 158 & 41 & yes & 41 & 33 & $81 \%$ \\
\hline meas. 5 & 142 & 33 & 70 & 134 & -8 & no & $<$ LD & $/$ & $/$ \\
\hline meas. 6 & 110 & 29 & 62 & 154 & 44 & yes & 44 & 32 & $74 \%$ \\
\hline meas. 7 & 126 & 31 & 66 & 142 & 16 & no & $<$ LD & $/$ & $/$ \\
\hline meas. 8 & 138 & 33 & 69 & 138 & 0 & no & $<$ LD & $/$ & $/$ \\
\hline meas. 9 & 103 & 28 & 60 & 152 & 49 & yes & 49 & 32 & $65 \%$ \\
\hline meas. 10 & 104 & 28 & 60 & 123 & 19 & no & $<$ LD & $/$ & $/$ \\
\hline
\end{tabular}

\subsection{Accumulation of the results by summation of individual countings}

The objective of the accumulation is to synthesize the whole of this information in only one line. Again appears the problem to integrate, into this accumulation, information of the type " $<$ LD". However in this precise case the starting point of this synthesis is commonplace. Indeed, and for purely physical reasons, the two series of raw counts and background noise can be perceived like intermediate results partial of two single countings: a single background counting value during $10 \times T_{s}$ and a raw count single of the same duration. This simple report will make it possible to carry out the accumulation without being concerned with knowing if each result is higher or lower than its threshold of decision.

Thus a fundamental rule appears in this type of problem:

$\checkmark$ Rule No. 1: information of the phase of analysis of individual measurements (phase 3) should not be taken into account in the development of the accumulation and it is necessary to preserve, in the objective to carry out an accumulation, all information of phases 1 and 2 of all individual measurements, whatever they are, including when the net amounts are negative. 
TABLE II

Information to be preserved before accumulation.

\begin{tabular}{cccccc}
\hline & Phase 1 & \multicolumn{3}{c}{ Phase 2 } \\
\hline & $B k G_{i}$ & $L c_{\text {Neti }}$ & $L D_{\text {Neti }}$ & Gross $_{\text {Neti }}$ & Net $_{i}$ \\
meas. 1 & 100 & 28 & 59 & 143 & 43 \\
$\vdots$ & $\vdots$ & $\vdots$ & $\vdots$ & $\vdots$ & $\vdots$ \\
meas. 10 & 104 & 28 & 60 & 123 & 19 \\
\hline
\end{tabular}

The operation of accumulation consists in this particular case to consider a single measurement with background value $B k G_{\Sigma}=\sum_{i=1}^{n} B k G_{i}(3)$ and a gross measurement value $\operatorname{Gross}_{\Sigma}=\sum_{i=1}^{n} \operatorname{Gross}_{i}$. Insofar as the sum preserves the Poisson character of the counting values, these two cumulated counting values make it possible to apply the same procedure as previously.

\section{Phase 1: the construction of the decision-making aid tool of on the cumulated} result

- Background counting value equal to $B k G_{\Sigma}$.

- Determination of the decision threshold "accumulation": $L c_{\Sigma N e t}=k_{1-\alpha} \sqrt{2 B k G_{\Sigma}}$ (4).

- Determination of the detection limit "accumulation" $L D_{\Sigma N e t}=k_{1-\beta}^{2}+2 L c_{\Sigma N e t}$ (5).

In equation (4), 1 extra count was not added to the background variance for simplicity.

\section{Phase 2: cumulated sample measurement}

- Gross sample count: the result obtained is noted $\operatorname{Gross}_{\Sigma}$.

- Determination of net counting value $\operatorname{Net}_{\Sigma}=\operatorname{Gross}_{\Sigma}-B k G_{\Sigma}$.

\section{Phase 3: analysis of the cumulated result}

- Decision threshold test $N e t_{\Sigma}>L c_{\Sigma \mathrm{Net}}$ ?

- If "yes" the effect is considered detected. Estimation of true average counting and associated uncertainty $\mu_{N e t_{\Sigma}}=N e t_{\Sigma} \pm k \sqrt{N e t_{\Sigma}+2 B k G_{\Sigma}}$.

If "not" the effect is regarded as not detected. Final expression of the result: $"<L D " \Leftrightarrow 0<\mu_{\text {Net }}<L D$. 
It will be noted that the statistic of interest $N e t_{\Sigma}$ is also equal to $N e t_{\Sigma}=\sum_{i=1}^{n} N e t_{i}$.

Applied to the previous example the following cumulated result is obtained:

TABLE III

Accumulation by summation.

\begin{tabular}{lccccccccc}
\hline & Phase 1 & \multicolumn{3}{c}{ Phase 2 } & \multicolumn{3}{c}{ Phase 3 } \\
\hline & $B k G_{\Sigma}$ & $L c_{\Sigma \text { Net }}$ & $L D_{\Sigma \text { Net }}$ & Gross $_{\Sigma}$ & Net & Net $>$ Lc? & Result & $\begin{array}{c}\text { Uncertainty } \\
(\mathrm{k}=2)\end{array}$ & $\begin{array}{c}\text { Relative } \\
\text { uncertainty }\end{array}$ \\
\hline $\begin{array}{l}\text { Accumulation } \\
\text { by summation }\end{array}$ & 1149 & 94 & 192 & 1422 & 273 & yes & 273 & 101 & $37 \%$ \\
\hline
\end{tabular}

The obvious result showing and justifying the general interest of the accumulation is here the final relative uncertainty equal to $37 \%$, whereas for the whole of the individual results, the average of the relative uncertainties is much higher (see Tab. I or II above). One second less obvious indication, but of interest to be notified, is the fact that the end result in terms of net counting value (273) is now largely higher not only than the decision threshold but also than the detection limit (192). That confirms that the presence of radioactivity is confirmed with a very great probability ${ }^{7}$, whereas five individual measurements on the ten did not confirm this presence. Concluding from this last remark that the probability for the sample to be nonradioactive could have been be equal to $50 \%$ would have been strong pessimist (or extremely optimist if it had been preferred that it is not so).

\subsection{Determination of the decision threshold on the accumulation starting from the individual thresholds of decision}

The accumulation method used here did not require knowing preliminary $n$ individual decision thresholds and detection limits, which seems to contradict the rule No. 1 which recommends keeping them. In fact we will show now that these values can be employed to directly find the decision threshold suitable for the cumulated value.

${ }^{7}$ Rigorous calculation shows that with such values the residual probability that the' sample is nonradioactive is equal to $3 \times 10^{-8}$. 
If one considers relations 1, 2 and 4, one can write:

$\left\{\begin{array}{l}\text { (1) } L c_{\Sigma N e t}=k_{1-\alpha} \sqrt{2 B k G_{\Sigma}} \\ \text { (2) } B k G_{\Sigma}=\sum_{i=1}^{n} B k G_{i} \\ \text { (4) } L c_{\text {Neti }}=k_{1-\alpha} \sqrt{2 B k G_{i}}\end{array} \Rightarrow\left\{\begin{array}{l}L c_{\Sigma N e t}=k_{1-\alpha} \sqrt{2 \sum_{i=1}^{n} B k G_{i}} \\ B k G_{i}=\frac{L c_{\text {Neti }}^{2}}{2 k_{1-\alpha}^{2}}\end{array} \Rightarrow L c_{\Sigma N e t}=k_{1-\alpha} \sqrt{2 \sum_{i=1}^{n} \frac{L c_{N e t i}^{2}}{2 k_{1-\alpha}^{2}}}=\sqrt{\sum_{i=1}^{n} L c_{N e t i}^{2}}\right.\right.$.

One thus obtains a simple relation between the decision threshold on the cumulated net value and the partial decision thresholds. It is important to note that this relation is similar to the relation between uncertainty on the cumulated result and the partial results. Indeed with $u_{\Sigma}$ uncertainty associated to $\operatorname{Net}_{\Sigma}$ and $u_{i}$ uncertainties associated to the partial results $\mathrm{Net}_{i}$, it is well known that the relation $N e t_{\Sigma}=\sum_{i=1}^{n} N e t_{i}$ allows expressing associated uncertainty according to the relation $u_{\Sigma}=\sqrt{\sum_{i=1}^{n} u_{i}^{2}}$. This analogy is not worth demonstration, but becomes more relevant if one remembers that basically $L c=k_{1-\alpha} \sigma_{H 0}$ (Vivier and Aupiais, 2007), with $\sigma_{H 0}$ the standard deviation of the distribution of the measurements under $H_{0}$ hypothesis (nonradioactive sample). Being homogeneous with a standard deviation, the decision thresholds "are propagated" in the model of the cumulated result following the same algebra as uncertainties ${ }^{8}$. This report makes it possible to state the following rule:

$\checkmark$ Rule No. 2: the decision thresholds follow an algebra of standard deviation and are composed in operations of accumulation according to the same formula as uncertainties.

This powerful rule will enable us to carry out an accumulation of ten measurements lots by carrying out a "natural" sum but by considering the averages of the background and gross counting values.

Concerning the limit of detection, the rigorous resolution is in general more delicate (except in this example, cf. Eq. (5)) insofar as the limit is not perfectly homogeneous with a standard deviation because of the term $k^{2}{ }_{1-\beta}$ in the expression (5). However by keeping the approximate relation $L D \approx 2 L c$ (the beta and alpha

\footnotetext{
${ }^{8}$ In the approach of the standard ISO 11929 one finds this property, insofar as the decision threshold is written $L c=k_{1-\alpha} \tilde{u}(0)$.
} Although conceptually debatable, $\tilde{u}(0)$ is also a standard deviation. 
risk errors are assumed to be the same) usually used, one can estimate the cumulated detection limit while applying:

- either the rule No. 2 on the individual detection limits. As example following this rule one obtains in our example $L D_{\Sigma N e t} \approx \sqrt{\sum_{i=1}^{n} L D_{\text {Neti }}^{2}}=200$;

- or directly the expression $L D_{\Sigma N e t} \approx k_{1-\beta}^{2}+2 L c_{\Sigma N e t}$ giving here $L D_{\Sigma N e t} \approx 192$.

These approximations are admissible as the thresholds and limits calculated starting from the experimental values are, like all experimental statistics, sullied with uncertainty. A calculation show here that the uncertainty-type $(\mathrm{k}=1)$ on the exact value of the detection limit is equal to $u_{L D_{\Sigma}} \approx 5$ (Vivier and Aupiais, 2007), that is to say an expanded uncertainty $(\mathrm{k}=2)$ about $u_{L D_{\Sigma}} \approx 10$, which makes it possible to accept these approximations.

\subsection{Accumulation of the results by average of the individual results}

Although less naturalness on a physical level, it is quite intuitive to synthesize these ten measurements by carrying out the average of the counting values over one duration $T_{s}$. One can note that this average has a sense insofar as countings are carried out under conditions of repeatability for identical durations. There still while following the rule No. 1, i.e. without being concerned with knowing if the individual results are higher or not than the individual decision thresholds, one can write the final result cumulated on the statistics of interest:

$$
\overline{N e t}_{n}=\frac{\sum_{i=1}^{n} N e t_{i}}{n}=27.3 \text {. }
$$

One can then put the question to know if this mean value is significant or not, which forces to determine a decision threshold $L c$ coherent with these statistics. By noting that uncertainty $u_{\overline{N e t}_{n}}$ associated to $\overline{N e t}_{n}$ is equal to:

$$
u_{\mathrm{Net}_{n}}=\frac{1}{n} \sqrt{\sum_{i=1}^{n} u_{i}^{2}}
$$

From which one can deduce by observing the rule No. 2 that the "cumulated" decision threshold is equal to:

$$
L c_{\overline{N e t_{n}}}=\frac{1}{n} \sqrt{\sum_{i=1}^{n} L c_{\text {Neti }}^{2}}(6) .
$$


That is to say here $L c_{\overline{\text { Net }_{10}}}=9.4$. The accumulation by average operation makes it possible to obtain following information:

TABLE IV

Accumulation by average.

\begin{tabular}{cccccccccc}
\hline & \multicolumn{1}{c}{ Phase 1 } & \multicolumn{2}{c}{ Phase 2 } & \multicolumn{3}{c}{ Phase 3 } \\
\hline & $\overline{B k G}_{n}$ & $L c_{\overline{N e t}_{n}}$ & $L D_{\overline{N e t}_{n}}$ & $\overline{G r o s s}_{n}$ & $\overline{N e t}_{n}$ & $\begin{array}{c}\text { Net }> \\
\text { Lc? }\end{array}$ & Result & $\begin{array}{c}\text { Expanded } \\
\text { uncertainty } \\
(\mathrm{k}=2)\end{array}$ & $\begin{array}{c}\text { Relative } \\
\text { uncertainty }\end{array}$ \\
Average & 114.9 & 9.4 & 20.0 & 142.2 & 27.3 & yes & 27.3 & 10 & $37 \%$ \\
\hline
\end{tabular}

In this particular case of repeatability, the individual decision thresholds are all of the same order of magnitude (see Tab. I). There is then the approximate relation $\sum_{i=1}^{n} L c_{N e t i}^{2} \approx n \cdot \overline{L c}_{N e t}^{2}$ and the relation (6) can be approximated according to the relation:

$$
L c_{\overline{N e t_{n}}} \approx \frac{1}{n} \sqrt{n \cdot \overline{L c}^{2}}=\frac{\overline{L c_{\text {Net }}}}{\sqrt{n}}(7) \text {. }
$$

This last relation shows that the decision threshold on the mean value decrease like the inverse of the square root of the number of individual measurements and show still here the interest of such accumulation. It will be noted that uncertainty associated with the average decreases in the same proportions.

Note: an error which one can make is to determine here a decision threshold according to the same algebra which the accumulation, is here $L c_{\overline{N e t_{n}}}=\overline{L c_{N e t}}$.

If one had eliminated from the final assessment the five values corresponding to the declaration" < LD", one would have obtained a net mean value $\overline{N e t}_{5}{ }_{5}=46$ instead of $\overline{N e t}_{10}=27$. The values presented here come from a data-processing simulation and the true net average is equal to $\mu_{N e t}=23$. This simple example shows that not taking into account measurements of the type " $<\mathrm{LD}$ " in the accumulation can give biased positive final values.

For this reason, it is important not to make disappear the experimental values of counting operation thus that of the decision thresholds in the tables of individual results, if these results are likely to be one day cumulated in a way or of another (rule No. 1). This is particularly true in environmental or discharge measurements, 
when the whole of measurements are carried out over great periods. It arrives then too often that the filed results make disappear the rough experimental data to store only information of the type "<LD", information not usable in the accumulation.

To illustrate a completely no-intuitive result, it is possible that all the partial results (Tab. V) are found nonsignificant $(N e t<L c)$, whereas the accumulation (Tab. VI) makes it possible to highlight a proven radioactivity (with always a risk error lower than the risk of second species $\beta$ ).

TABLE V

Example with 10 negative individual results $(<\mathrm{Lc})$.

\begin{tabular}{ccccccccc}
\hline & Phase 1 & \multicolumn{4}{c}{ Phase 2 } & \multicolumn{3}{c}{ Phase 3} \\
\hline$B k G_{i}$ & $L c_{\text {Neti }}$ & $L D_{\text {Neti }}$ & Gross $_{i}$ & Net $_{i}$ & $\begin{array}{c}\text { Net }> \\
\text { Lc? }\end{array}$ & Result & $\begin{array}{c}\text { Expanded } \\
\text { uncertainty } \\
\text { uncertainty }\end{array}$
\end{tabular}

$(\mathrm{k}=2)$

\begin{tabular}{|c|c|c|c|c|c|c|c|c|c|}
\hline meas. 1 & 119 & 30 & 64 & 122 & 3 & no & $<\mathrm{LD}$ & 1 & I \\
\hline meas. 2 & 119 & 30 & 64 & 136 & 17 & no & $<\mathrm{LD}$ & I & I \\
\hline meas. 3 & 126 & 31 & 66 & 137 & 11 & no & $<\mathrm{LD}$ & I & I \\
\hline meas. 4 & 144 & 33 & 70 & 139 & -5 & no & $<\mathrm{LD}$ & I & I \\
\hline meas. 5 & 131 & 32 & 67 & 151 & 20 & no & $<\mathrm{LD}$ & I & I \\
\hline meas. 6 & 119 & 30 & 64 & 145 & 26 & no & $<\mathrm{LD}$ & I & I \\
\hline meas. 7 & 127 & 31 & 66 & 130 & 3 & no & $<\mathrm{LD}$ & I & I \\
\hline meas. 8 & 113 & 29 & 63 & 125 & 12 & no & $<\mathrm{LD}$ & I & I \\
\hline meas. 9 & 127 & 31 & 66 & 145 & 18 & no & $<\mathrm{LD}$ & I & I \\
\hline meas. 10 & 111 & 29 & 62 & 140 & 29 & no & $<\mathrm{LD}$ & I & I \\
\hline
\end{tabular}

TABLE VI

Accumulation by average. Positive end result ( $>$ Lc).

\begin{tabular}{lccccccccc}
\hline & \multicolumn{3}{c}{ Phase 1 } & \multicolumn{3}{c}{ Phase 2 } & \multicolumn{3}{c}{ Phase 3 } \\
\hline & $\overline{B k G}_{n}$ & $L c_{{\overline{N e t_{n}}}_{n}}$ & $L D_{\overline{N e t}_{n}}$ & $\overline{G r o s s}_{n}$ & $\overline{N e t}_{n}$ & $\begin{array}{c}\text { Net }> \\
\text { Lc? }\end{array}$ & Result & $\begin{array}{c}\text { Expanded } \\
\text { uncertainty } \\
(\mathrm{k}=2)\end{array}$ & $\begin{array}{c}\text { Relative } \\
\text { uncertainty }\end{array}$ \\
$\begin{array}{c}\text { Accumulation } \\
\text { by average }\end{array}$ & 123.6 & 9.7 & 20.7 & 137 & 13.4 & yes & 13.4 & 10 & $76 \%$ \\
\hline
\end{tabular}

These results were obtained by simulation with a true value $\mu_{N e t}=18$. It shows that 10 negative results are not a final proof of an absence of radioactivity. The "average" of ten "not" isn't "not". 
Note 1: an error which one can make in a similar case would be to declare that ten nonsignificant measurements can lead only to one nonsignificant accumulation, bringing to declare "lower than the detection limit on cumulated result". If in addition this detection limit is wrongly (but usually) calculated like the average of the individual limits, the results of Table VI would lead to a final assessment $" \mu_{N e t}<65 "$ instead of $\hat{\mu}_{N e t}=13 \pm 10$, that is to say still in terms of high limit of confidence interval " $\mu_{\text {Net }}<28 "$.

Note 2: an indication showing without erudite calculation that the results of table V encourage to think that there is "something" is the following report: when one repeats measurements of a nonradioactive sample, then the net values are on average negative once on two times. However here nine results on ten are positive, which authorizes to think that the probability that the sample could be free of radioactivity is weak.

The detection limit associated to $L c_{\overline{N e t}_{n}}$ is calculated according to a similar formula:

$$
L D_{\overline{\text { Net }_{n}}}=\frac{1}{n} \sqrt{\sum_{i=1}^{n} L D_{N e t i}^{2}} .
$$

It is easy to see that the detection limit of the mean value decrease approximately as the inverse of the square root of the number of individual measurements, just like the decision threshold $\left(L c_{\overline{\mathrm{Net}_{n}}}\right)$.

\subsection{Ideal situations of application of the accumulation of decision threshold and opposite case}

The rules stated above are always applicable as soon as the mean of measurements values have a physical or statistical sense. On the other hand obtaining such spectacular results appears only when various measurements can be regarded as achievements of random variables of homogeneous parameters.

This condition is observed in the case of the repetition of measurements of the same sample (cases No. 1 and 2). If the samples are different (case No. 3), picked up in different point or different dates, the interest of the accumulation appears when these samples remain homogeneous and representative of the quite same average conditions. Thus we saw that the preceding example obtained by simulation corresponds if the results obey the same real mean value $\mu_{N e t}=18$. This 


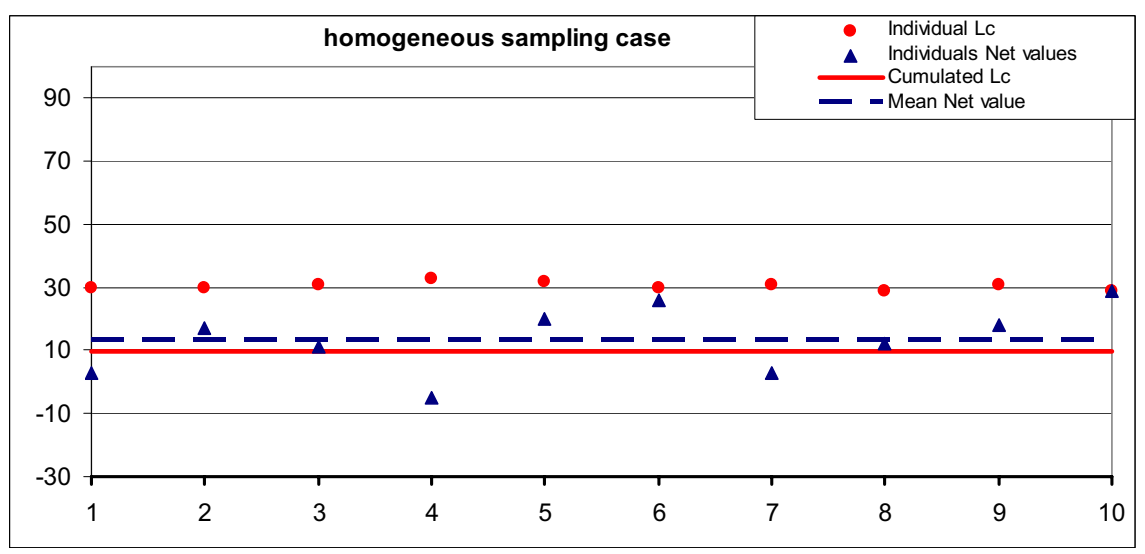

Figure 1 - Homogeneous experimental values (This figure is available in color in electronic form).

condition of homogeneity of the individual results of the preceding example (Tabs. V and VI) is obvious with a graphic representation (Fig. 1).

When this condition is not observed, the result can, contrary to what we saw until now, make a very significant individual measurement disappear when averaging all results. The scenario-type of such a situation meets for example when the searched activity is present only in one sample, which can be the case in the search for a point source ("hot spot") or in the case of periodic samplings, with an accidental and isolated contamination in time.

In such a scenario, it is hardly beneficial to carry out an accumulation of measurements: the contaminated sample can then be measured to a significant degree positively, whereas the average result, extended to the whole of the other not contaminated samples, can appear overall negative. The "accidental" value disappears in the average as shows in the following example.

The sample No. 5 is significantly measured positive (Fig. 2), in such way that its contamination is without ambiguity (assume the activity uncertainty is small compared to the critical value), but this positive case disappears in the accumulation operation, the other samples being not contaminated.

This report is a part of a more general report that it is good not to lose sight in the use of statistical tools. The latter are often very relevant when they are interested in values resulting from homogeneous population, but often lose their sense when dealing with very heterogeneous populations. Specific and relevant statistical methods make it possible to avoid such a pitfall, such as discriminating analysis for example. 


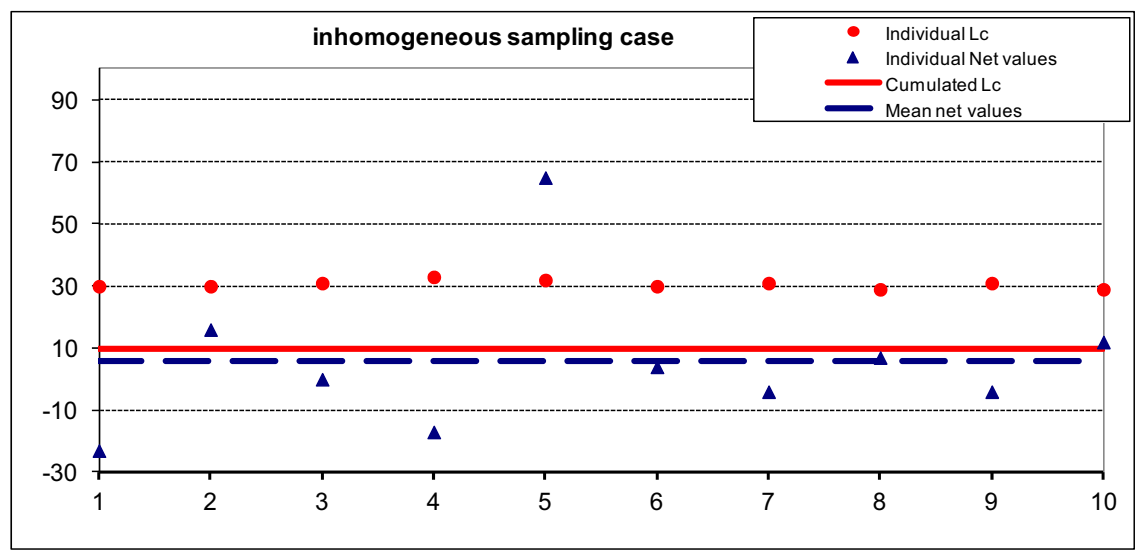

Figure 2 - Inhomogeneous experimental values (This figure is available in color in electronic form).

\section{Accumulation in gamma spectrometry (case No. 2)}

\subsection{Calculation of the decision threshold on an accumulation by weighted average of the measured activities}

The measurement of a multi-gamma emitter by spectrometry is another case where the accumulation of results is usually employed. The experimental situation corresponds here to the case No. 2, known as of reproduction of measurements. Indeed from one peak to another, values of total absorption efficiencies $\varepsilon_{i}$ and emission intensities $\gamma_{i}$ are generally different. This situation is similar to multiple measurements in situations of reproducibility. Each peak "i" makes it possible to estimate the value of the true average activity $\tilde{\mathcal{A}}$, value obviously common to all the peaks, by the measured activity, is $\hat{\mathcal{A}}_{i}=\mathcal{A}_{\text {mesuré } i}=\frac{S_{\text {Neti }}}{\varepsilon_{i} \cdot \gamma_{i} \cdot t}$, with $S_{\text {Neti }}$ the net surface of the peak and $\gamma_{i}$ intensity of emission. Here still the conditions of reproducibility lead to the fact that uncertainties $u_{i}=\sqrt{S_{N e t i}+2 S_{B k G i}}$ (the background width is assumed to be the same as the peak width) associated to each peak do not have vocation to be of the same order of magnitude, nor moreover the decision thresholds $L c_{\mathcal{A} i}=\frac{L c_{\text {Neti }}}{\varepsilon_{i} \cdot \gamma_{i} \cdot t}$ in specific terms of activities to each peaks. $S_{B k G i}$ is the background surface estimation under peak by a trapezium. 
It is known that in this situation the best estimator of the true value is then the weighted average of all measurements (equivalent to least mean-squares values as well as maximum likelihood):

$$
\hat{\mathcal{A}}_{\text {weighted }}=\frac{\sum_{i=1}^{n} \frac{1}{u_{i}^{2}} \mathcal{A}_{i}}{\sum_{i=1}^{n} \frac{1}{u_{i}^{2}}}
$$

To this estimator uncertainty corresponds: $u_{\text {weighted }}=\sqrt{\frac{1}{\sum_{i=1}^{n} \frac{1}{u_{i}^{2}}}}$.

By observing the rule No. 2 one can then calculate the decision threshold for testing the significant character or not weighted average activity starting from the thresholds of each peak:

$$
\operatorname{Lc}\left(\hat{\mathcal{A}}_{\text {weigh. }}\right)=\sqrt{\frac{1}{\sum_{i=1}^{n} \frac{1}{L c_{\mathcal{A} i}^{2}}} .}
$$

The interest of this accumulation is still immediate here since the preceding relation makes it possible to write $\operatorname{Lc}\left(\hat{\mathcal{A}}_{\text {weigh. }}\right) \leq \operatorname{Min}\left(L c_{i}\right)$. The "accumulated" decision threshold is smaller than the smaller partial decision threshold.

The detection limit is calculated like the decision threshold by

$$
L D\left(\hat{\mathcal{A}}_{\text {pond. }}\right) \approx \sqrt{\frac{1}{\sum_{i=1}^{n} \frac{1}{L D_{\mathcal{A}}^{2}}}} .
$$

\subsection{Application in the search of barium 133 in a gamma spectrum}

The spectrum below is a spectrum acquired during $600 \mathrm{~s}$ with an important background noise generated in the field of emission of barium 133 by a source of caesium 137. The identification of the five ROI of barium 133 was carried out under optimal conditions (Vivier et al., 2010). The analysis of the spectrum on each ROI of Barium 133 does not make it possible to detect it, although it was present in the sample. 


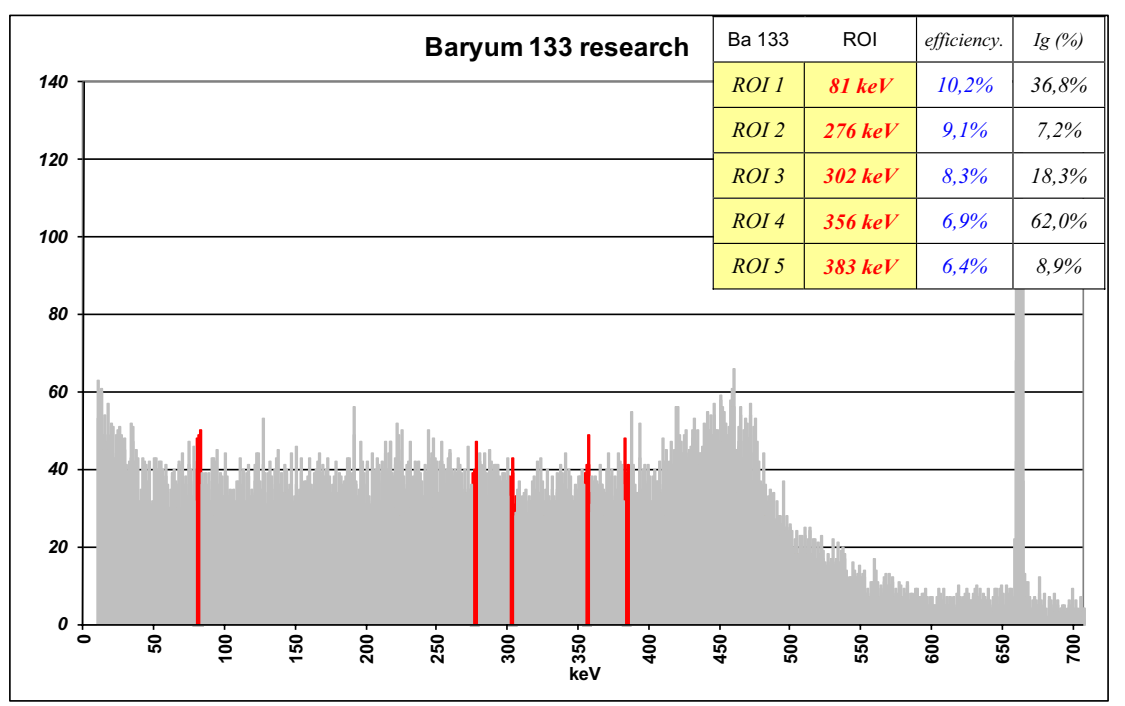

Figure 3 - Spectrum gamma with a priori ROI for barium 133 (This figure is available in color in electronic form).

On the other hand the accumulation of these five informations makes it possible to highlight barium 133: the weighted average activity is equal to $1.8 \mathrm{~Bq}$ (column 3 following Eq. (8)) for a decision threshold cumulated of $1.3 \mathrm{~Bq}$ (column 1 following Eq. (9)).

TABLE VII

Accumulation of the individual results of the peaks of barium 133.

\begin{tabular}{|c|c|c|c|c|c|c|c|c|c|c|}
\hline & & Phase 1 & & & Phas & & & $\mathrm{Ph}$ & 3 & \\
\hline & $\begin{array}{c}\text { BkG } \\
\text { under } \\
\text { peak }\end{array}$ & $\begin{array}{c}(1) \\
\text { Lc }(\mathrm{Bq}) \\
\text { per peak }\end{array}$ & $\begin{array}{c}(2) \\
\mathrm{LD}(\mathrm{Bq})\end{array}$ & $\begin{array}{l}\text { Gross } \\
\text { surface }\end{array}$ & $\begin{array}{c}\text { Net } \\
\text { surface }\end{array}$ & $\begin{array}{c}(3) \\
\text { Measured } \\
\text { activity per } \\
\text { peak }\end{array}$ & $\begin{array}{c}(4) \\
A_{i}>L c ?\end{array}$ & $\begin{array}{c}(5) \\
\text { Result }\end{array}$ & $\begin{array}{c}(6) \\
\text { Abs. } \\
\text { uncert. } \\
(\mathrm{k}=2)\end{array}$ & $\begin{array}{c}\text { (7) } \\
\text { Rel. } \\
\text { uncert. }\end{array}$ \\
\hline $81 \mathrm{keV}$ & 423 & $2.2 \mathrm{~Bq}$ & $5 \mathrm{~Bq}$ & 472 & 49 & $2.2 \mathrm{~Bq}$ & no & $<\mathrm{LD}$ & $2.7 \mathrm{~Bq}$ & $122 \%$ \\
\hline $276 \mathrm{keV}$ & 410 & $12.4 \mathrm{~Bq}$ & $26 \mathrm{~Bq}$ & 416 & 6 & $1.5 \mathrm{~Bq}$ & no & $<\mathrm{LD}$ & 14.7 Bq & $958 \%$ \\
\hline $302 \mathrm{keV}$ & 383 & $5.2 \mathrm{~Bq}$ & $11 \mathrm{~Bq}$ & 403 & 20 & $2.2 \mathrm{~Bq}$ & no & $<\mathrm{LD}$ & $6.2 \mathrm{~Bq}$ & $280 \%$ \\
\hline $356 \mathrm{keV}$ & 384 & $1.8 \mathrm{~Bq}$ & $4 \mathrm{~Bq}$ & 418 & 34 & $1.3 \mathrm{~Bq}$ & no & $<\mathrm{LD}$ & $2.2 \mathrm{~Bq}$ & $167 \%$ \\
\hline $383 \mathrm{keV}$ & 412 & $14.3 \mathrm{~Bq}$ & $30 \mathrm{~Bq}$ & 440 & 28 & $8.2 \mathrm{~Bq}$ & no & $<\mathrm{LD}$ & $17.1 \mathrm{~Bq}$ & $208 \%$ \\
\hline & CUMUL & $1.3 \mathrm{~Bq}$ & $2.8 \mathrm{~Bq}$ & & & $1.8 \mathrm{~Bq}$ & yes & $1.8 \mathrm{~Bq}$ & $1.6 \mathrm{~Bq}$ & $92 \%$ \\
\hline
\end{tabular}


Here again the accumulation makes it possible to improve with a significant degree the capacities of detection. The detection limit calculated by equation (10) is equal here to $2.8 \mathrm{~Bq}$ instead of $4 \mathrm{~Bq}$ if one is satisfied with the ROI at $356 \mathrm{keV}$, having the lower partial detection limit. Note that the absolute and relative uncertainties are given here with each individual result, even it is not done in practice. But once again it is a good indication of the capability of obtaining a significant result when cumulating several nonsignificant results.

\subsection{Improved detection limit of a multiple-detector system}

In gamma spectrometry, multiple detectors are often used to improve the detection capability. The sample can be a point source or a volume source with uniform distribution of radioactivity (like a waste container). If all detectors have similar characteristics and if the detector-source geometries are almost identical, the system can be considered under case No. 2. Then rule No. 2 and the uncertainty weighted average method are applicable. It is often desired to quantify the overall detection capability with the detection limit. In Table VIII, numerical examples are given for illustration. For each detector, simulated peak background and gross counts are listed. Results similar to the Ba-133 example above are given (live time at $1000 \mathrm{~s}$, branching ratio at 1 and efficiencies at $100 \%$ ).

TABLE VIII

Improved cumulative detection limit with multiple detectors.

\begin{tabular}{lccccccccccc}
\hline & \multicolumn{3}{c}{ Phase 1 } & \multicolumn{4}{c}{ Phase 2 } & \multicolumn{3}{c}{ Phase 3 } \\
\hline & $\begin{array}{c}\text { BkG } \\
\text { under } \\
\text { peak }\end{array}$ & Lc (Bq) & LD (Bq) & $\begin{array}{c}\text { Gross } \\
\text { surface }\end{array}$ & $\begin{array}{c}\text { Net } \\
\text { surface }\end{array}$ & $\begin{array}{c}\text { Measured } \\
\text { activity }\end{array}$ & $\mathrm{A}_{\mathrm{i}}>\mathrm{Lc}$ & Result & $\begin{array}{c}\text { Abs. } \\
\text { uncert. } \\
\text { (k=2) }\end{array}$ & $\begin{array}{c}\text { Rel. } \\
\text { uncert. }\end{array}$ \\
Det. 1 & 126 & $26.0 \mathrm{~Bq}$ & $46.6 \mathrm{~Bq}$ & 137 & 11 & $9.2 \mathrm{~Bq}$ & No & $<\mathrm{LD}$ & 27.0 & $/$ \\
Det. 2 & 113 & $24.7 \mathrm{~Bq}$ & $44.3 \mathrm{~Bq}$ & 125 & 12 & $10 \mathrm{~Bq}$ & No & $<\mathrm{LD}$ & 25.7 & $/$ \\
Det. 3 & 131 & $26.6 \mathrm{~Bq}$ & $47.4 \mathrm{~Bq}$ & 151 & 20 & $20 \mathrm{~Bq}$ & No & $<\mathrm{LD}$ & 27.9 & $/$ \\
\hline Det. 4 & 111 & 24.5 & 43.9 & 140 & 29 & 29 & Yes & 29 & 26.4 & $/$ \\
& CUMUL & $12.7 \mathrm{~Bq}$ & $22.7 \mathrm{~Bq}$ & & & $14.9 \mathrm{~Bq}$ & Yes & $14.9 \mathrm{~Bq}$ & $13.3 \mathrm{~Bq}$ & $/$ \\
\hline
\end{tabular}

From above table, the cumulative detection limit $(22.7 \mathrm{~Bq})$ is about half of the averaged detection limit $(45 \mathrm{~Bq})$. It is easy to see that the cumulative detection limit decreases as $\sqrt{n}$ ( $n$ the number of detectors). Furthermore, if one detector is deteriorated with large peak background noise or degraded efficiency, the overall detection limit is not be affected much since bad results are weighted much less and it's always better than at least one of the best performing detector. This is an advantage of using the uncertainty weighted method. If straight average method is 
used, the one from the deteriorated detector can skew the cumulative result considerably due to equal weighting.

\section{Accumulation on environment sample (case No. 3) achieved by IRSN}

If one considers $n$ samples of rainwater collected periodically in the same geographical place, it is possible to cumulate this information in the sense to obtain "the average content of a radionuclide given in a geographical area and over one specified period". Thus each sample can be regarded as part of a unit made up of the sum of all the samples. The measurand of interest is then either the sum of the activities of all samples, or their average value. The first quantity is relevant when one is interested in assessments of rejections, the second is more relevant if one is interested in the mean radioactivity of the environment.

In all cases it is important to note an important difference with the preceding cases. Here each sample is likely to contain a partial true activity $\tilde{\mathcal{A}}_{i}$ significantly different from sample to another, whereas in the two preceding cases this true value was the same one for all measurements. We will see that this characteristic impacts the calculation of the detection limit compared to the preceding cases, the cumulated decision threshold being insensitive to this potential dispersion of the true values. We exclude here the case of an accidental and massive punctual contamination, like discussed in Chapter 2.5.

Numerical application (Tab. IX) with sixteen periodic samples for tritium measurement in rainwater. Counting time of measurements is $200 \mathrm{~min}$. The sixteen measured activity (column 8) are significative of a normal homogeneous population, as it can be seen with a Kolmogorov test. So in respect to Chapter 2.5, these values are in the case of application of accumulation.

The accumulation is done here by weighted average. One notes a relative variability $\sigma_{\text {rel. } \varepsilon}$ of efficiencies about $10 \%$ around an average efficiency equal to $28 \%$. The calculation of the weighted average activity takes account (rule No. 1) of the 16 results, including "negative activities". These should not be rejected although a true activity can be only positive. Indeed a negative single measurement cannot be regarded as an estimator of the true value, but has still real informational contents. In practices it is important to file the entirety of the values of measurements, positive or negative, and not to make them disappear by replacing them purely and simply by the indication " $<$ LD" when it is the case.

This is a recommendation made by several scientific authorities like Royal Society of Chemistry (MARLAP, 2004) or the Federal Agency of Environmental 
TABLE IX

Periodic measurements of tritium in rainwater.

\begin{tabular}{|c|c|c|c|c|c|c|c|c|c|c|c|c|}
\hline & \multicolumn{5}{|c|}{$\begin{array}{l}\text { Decision threshold an detection } \\
\text { limit calculation }\end{array}$} & \multicolumn{3}{|c|}{$\begin{array}{c}\text { Samples measurements } \\
\text { values }\end{array}$} & \multicolumn{4}{|c|}{$\begin{array}{l}\text { Testing values and expressed } \\
\text { individual results }\end{array}$} \\
\hline & $\mathrm{BkG}$ & $\begin{array}{l}\text { Lc } \\
\text { Net }\end{array}$ & $\mathcal{E}(\%)$ & $\begin{array}{c}\mathrm{Lc} \\
(\mathrm{Bq} / \mathrm{L})\end{array}$ & $\begin{array}{c}\mathrm{LD} \\
(\mathrm{Bq} / \mathrm{L})\end{array}$ & Gross & Net & $\begin{array}{c}\text { Measure } \\
\text { d activity } \\
(\mathrm{Bq} / \mathrm{L})\end{array}$ & $\begin{array}{l}\text { Net > } \\
\text { Lc? }\end{array}$ & $\begin{array}{l}\text { Declaratio } \\
\mathrm{n}(\mathrm{Bq} / \mathrm{L})\end{array}$ & $\begin{array}{l}\text { Uncertainty } \\
(\mathrm{Bq} / \mathrm{L})\end{array}$ & $\begin{array}{l}\text { Rel. } \\
\text { uncert. }\end{array}$ \\
\hline Samp. 1 & 1020 & 89 & $21 \%$ & 3.45 & 7.04 & 1024 & 4 & 0.16 & NO & $<\mathrm{LD}$ & I & I \\
\hline Samp. 2 & 857 & 81 & $30 \%$ & 2.23 & 4.56 & 890 & 33 & 0.90 & NO & $<\mathrm{LD}$ & I & I \\
\hline Samp. 3 & 823 & 80 & $31 \%$ & 2.15 & 4.41 & 985 & 162 & 4.38 & YES & $\begin{array}{c}4.4 \\
\mathrm{~Bq} / \mathrm{L}\end{array}$ & $\begin{array}{c}+/-2.3 \\
\mathrm{~Bq} / \mathrm{L}\end{array}$ & $51 \%$ \\
\hline Samp. 4 & 812 & 79 & $26 \%$ & 2.49 & 5.10 & 793 & -19 & -0.60 & NO & $<\mathrm{LD}$ & I & I \\
\hline Samp. 5 & 903 & 83 & $31 \%$ & 2.26 & 4.62 & 967 & 64 & 1.73 & NO & $<\mathrm{LD}$ & I & I \\
\hline Samp. 6 & 722 & 75 & $26 \%$ & 2.38 & 4.88 & 775 & 53 & 1.69 & NO & $<\mathrm{LD}$ & I & I \\
\hline Samp. 7 & 784 & 78 & $26 \%$ & 2.46 & 5.04 & 952 & 168 & 5.32 & YES & $\begin{array}{c}5.3 \\
\mathrm{~Bq} / \mathrm{L}\end{array}$ & $\begin{array}{l}+/-2.6 \\
\mathrm{~Bq} / \mathrm{L}\end{array}$ & $49 \%$ \\
\hline Samp. 8 & 1058 & 90 & $30 \%$ & 2.48 & 5.06 & 1117 & 59 & 1.62 & NO & $<\mathrm{LD}$ & I & I \\
\hline Samp. 9 & 735 & 75 & $26 \%$ & 2.39 & 4.89 & 881 & 146 & 4.63 & YES & $\begin{array}{c}4.6 \\
\mathrm{~Bq} / \mathrm{L}\end{array}$ & $\begin{array}{c}+/-2.5 \\
\mathrm{~Bq} / \mathrm{L}\end{array}$ & $54 \%$ \\
\hline Samp.10 & 1004 & 88 & $31 \%$ & 2.39 & 4.88 & 1002 & -2 & -0.05 & NO & $<\mathrm{LD}$ & I & I \\
\hline Samp.11 & 899 & 83 & $30 \%$ & 2.31 & 4.72 & 989 & 90 & 2.50 & YES & $\begin{array}{c}2.5 \\
\mathrm{~Bq} / \mathrm{L}\end{array}$ & $\begin{array}{c}+/-2.4 \\
\mathrm{~Bq} / \mathrm{L}\end{array}$ & $95 \%$ \\
\hline Samp.12 & 806 & 79 & $26 \%$ & 2.49 & 5.10 & 858 & 52 & 1.65 & NO & $<\mathrm{LD}$ & I & I \\
\hline Samp.13 & 772 & 77 & $26 \%$ & 2.51 & 5.14 & 797 & 25 & 0.81 & NO & $<\mathrm{LD}$ & I & I \\
\hline Samp.14 & 937 & 85 & $28 \%$ & 2.57 & 5.25 & 1000 & 63 & 1.90 & NO & $<\mathrm{LD}$ & I & I \\
\hline Samp.15 & 820 & 79 & $30 \%$ & 2.23 & 4.56 & 924 & 104 & 2.92 & YES & $\begin{array}{c}2.9 \\
\mathrm{~Bq} / \mathrm{L}\end{array}$ & $\begin{array}{c}+/-2.3 \\
\mathrm{~Bq} / \mathrm{L}\end{array}$ & $79 \%$ \\
\hline Samp.16 & 818 & 79 & $27 \%$ & 2.45 & 5.01 & 906 & 88 & 2.72 & YES & $\begin{array}{c}2.7 \\
\mathrm{~Bq} / \mathrm{L}\end{array}$ & $\begin{array}{l}+/-2.5 \\
\mathrm{~Bq} / \mathrm{L}\end{array}$ & $92 \%$ \\
\hline \multicolumn{4}{|c|}{$\begin{array}{c}\text { Accumulation by weighted } \\
\text { average }\end{array}$} & 0.60 & 1.22 & & & 2.07 & YES & $\begin{array}{l}2.07 \\
\mathrm{~Bq} / \mathrm{L}\end{array}$ & $\begin{array}{c}+/-0.6 \\
\mathrm{~Bq} / \mathrm{L}\end{array}$ & $30 \%$ \\
\hline
\end{tabular}


protection of the United States (AMC, 2001) We can quote the MARLAP here: "The laboratory should report each measurement result and its uncertainty as obtained (as recommended in Chapter 19) even if the result is less than zero". This does not want to say that it is necessary to have the whole of the results of measurement (values of raw count, background noise, net counting value, etc). In fact only the values of the measured activity and possibly the dispersion of the efficiencies (see Appendix 4) are necessary. It is perfectly conceivable to restore this result by specifying that it is lower than the detection limit but by also giving the value measured like its uncertainty.

As comparison, the fact of omitting the nonsignificant results leads to an average from approximately 3.73 . Thus compared to the result calculated by taking account of the whole of the values one introduces here a skew of almost $100 \%$. This is not a simple calculative abstraction but corresponds to the physical case where an operator would mix these 16 samples collected throughout the year and would wish to compare the result of measurement of the mixture with those of measurements of each samples.

It is thus possible to rigorously determine the annual mean value of the activity measured in these samples. If one admits the validity of each individual measurement, this operation of accumulation keeps any validity in so far as it has a sense. It is obvious that an accumulation of measurements of samples taken in various points at various times would not have any sense if the samples were not representative of a single measurand defined without ambiguity.

\section{Decision threshold on the weighted average activity}

As in the case of the gamma spectrometry the decision threshold associated with the weighted average activity is calculated like:

$$
L c\left(\hat{\mathcal{A}}_{\text {weigh. }}\right)=\sqrt{\frac{1}{\sum_{i=1}^{n} \frac{1}{L c_{i}^{2}}}} .
$$

One obtains a decision threshold on the average activity equal to $0.60 \mathrm{~Bq} . \mathrm{L}^{-1}$, whereas the individual decision thresholds are about $2.45 \mathrm{~Bq} \cdot \mathrm{L}^{-1}$. The gain there still is about $\sqrt{16}$.

Note: if the measurand of interest is the sum of the activities $\hat{\mathcal{A}}_{\Sigma}=\sum_{i=1}^{n} \hat{\mathcal{A}}_{i}$, instance in the annual statement of discharge calculated starting from the monthly 
discharges, then the application of the rule No. 2 is commonplace here and makes it possible to write:

- associated decision threshold: $L c\left(\sum_{i=1}^{n} \hat{\mathcal{A}}_{i .}\right)=\sqrt{\sum_{i=1}^{n} L c_{\mathcal{A} i}^{2}}$

- limit of associated detection: $L D\left(\sum_{i=1}^{n} \hat{\mathcal{A}}_{i .}\right)=\sqrt{\sum_{i=1}^{n} L D_{\mathcal{A} i}^{2}}$.

\section{Detection limit associated to the estimation by weighted average}

The dispersion of the efficiencies characterized by the relative standard deviation of the efficiencies discussed in Section $3\left(\sigma_{\text {rel.E }}\right)$ introduce a corrective term tending to increase the limit of detection. The latter is calculated according to the formula:

$$
L D\left(\hat{\mathcal{A}}_{\text {pond. }}\right)=\frac{1}{1-k_{1-\beta}^{2} \cdot \sigma_{\text {rel. }}^{2}} \cdot \sqrt{\frac{1}{\sum_{i=1}^{n} \frac{1}{L D_{i}^{2}}}} .
$$

This expression is similar to the expression of the detection limit in the standard ISO 11929 (ISO, 2009). The corrective term $1 /\left[1-k_{1-\beta}^{2} \cdot \sigma_{\text {rel. }}^{2}\right]$ is easily negligible when the efficiencies are little dispersed. For a beta risk equal to $2.5 \%$ the corrective term remains lower than 1.1 when the relative variability on the efficiencies remains lower than $15 \%$. It is necessary to have a relative variability of $36 \%$ so that this term of correction is equal to 2 .

In Appendix B, detailed discussions about the correction term above can be found. The application of the correction term to the detection limit can be made to measurements belonging to case No. 2 and case No. 3. For case No. 3, the periodic tritium measurement is a good example. For case No. 2, the multi-detector system is another example where the differences in the detector efficiencies can lead to an increase in the detection limit.

Note: beyond the examples given in this paper, the methods presented here have been validated by computer simulations.

\section{Conclusion}

The implementation of these methods, through the rules No. 1 and No. 2, can make it possible to lower considerably the decision thresholds and the detection 
limits in many situations: assessment of rejections, environmental measurements, waste, etc. Generally one can expect to decrease the decision thresholds and the detection limits by a factor of $\sqrt{n}$, when the number of cumulatable measurements is equal to $n$. These methods also make it possible to be freed from heavy statistical treatments or strongly skewed by taking into account rigorously the whole of information given by measurements. This rigor of treatment also gives the possibility of determining if the whole of the results give significant information on the global presence or not of an element. It is important to understand the measurement system and the data collected so that the appropriate cumulative method is applied to the whole measurements. If you improve your decision threshold that means that you have first understood the way your measurement works, and secondly you have improved it.

The application of these new methods by the Service of study and monitoring of the radioactivity in the environment of the IRSN, which manages annually about twenty thousand samples on the national territory, which give approximately about thirty thousand analyzes, should bring notable improvements in field of environment survey.

This installation should be made in a way in the year 2012, because it requires upstream a modification of the protocols of transfer of information, and downstream a methodology of careful analysis of the results, so that with each stage the announced results keep a physical sense.

\section{Appendix A: decision threshold on a sum of activity}

For an accumulation being carried out for example by summoning two activities, $\mathcal{A}_{\Sigma}=\mathcal{A}_{1}+\mathcal{A}_{2}$, one can write:

$$
\left\{\begin{array}{l}
\mathcal{A}_{1}=\frac{\text { Gross }_{1}-B k G_{1}}{\varepsilon_{1} \times T_{1}} \text { with } L c_{l[B q]}=\frac{k_{1-\alpha} \sqrt{2\left(B k G_{1}+1\right)}}{\varepsilon_{1} \times T_{1}}=k_{1-\alpha} \frac{\sqrt{2} \times \sigma_{\left[B k G_{1}\right]}}{\varepsilon_{1} \times T_{1}} \\
\mathcal{A}_{2}=\frac{\text { Gross }_{2}-B k G_{2}}{\varepsilon_{2} \times T_{2}} \text { avec } L c_{2[B q]}=\frac{k_{1-\alpha} \sqrt{2\left(B k G_{2}+1\right)}}{\varepsilon_{2} \times T_{2}}=k_{1-\alpha} \frac{\sqrt{2} \times \sigma_{\left[B k G_{2}\right]}}{\varepsilon_{2} \times T_{2}} .
\end{array}\right.
$$

If one remembers that the decision threshold is built on the distribution of the measured value of the activity under the $H_{0}$ hypothesis, namely a nonradioactive 
sample, one obtains the random variable "total activity":

$$
\left[\mathcal{A}_{\text {lot }}\right]_{H_{0}}=\left[\mathcal{A}_{1}\right]_{H_{0}}+\left[\mathcal{A}_{2}\right]_{H_{0}}=\frac{\left[B k G_{1}\right]-\left[B k G_{1}^{\prime}\right]}{\varepsilon_{1} \times T_{1}}+\frac{\left[B k G_{2}\right]-\left[B k G_{2}^{\prime}\right]}{\boldsymbol{\varepsilon}_{2} \times T_{2}}, \text { of null }
$$

average, and standard deviation:

$$
\sigma_{\left[A_{o l}\right]_{H o}}^{2}=\sigma_{\left[A_{1}\right]_{H o}}^{2}+\sigma_{\left[A_{2}\right]_{H o}}^{2}=\frac{\sigma_{\left[B k G_{1}\right]}^{2}+\sigma_{\left[B K G_{1}^{\prime}\right]}^{2}}{\left(\varepsilon_{1} \times T_{1}\right)^{2}}+\frac{\sigma_{\left[B k G_{2}\right]}^{2}+\sigma_{\left[B k G_{i}^{\prime}\right]}^{2}}{\left(\varepsilon_{2} \times T_{2}\right)^{2}}=\frac{2 \sigma_{\left[B k G_{1}\right]}^{2}}{\left(\boldsymbol{\varepsilon}_{1} \times T_{1}\right)^{2}}+\frac{2 \sigma_{\left[B k G_{2}\right]}^{2}}{\left(\boldsymbol{\varepsilon}_{2} \times T_{2}\right)^{2}} .
$$

The decision threshold for a a risk given is $L c_{\text {total }}=k_{1-\alpha} \times \sigma_{\left[A_{t o t}\right]_{H 0}}$.

By using the relations (A1) and (A2) one obtains naturally:

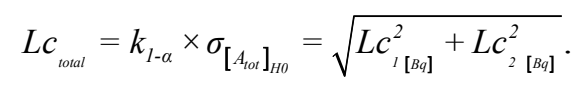

\section{Appendix B: taking into account of the dispersion of the efficiencies}

The problem consists in determining $L D_{[B q]}$ by taking account of dispersion on the efficiencies (uncertainty on each efficiency is supposed to be negligible, about a few \%). This variability of the efficiency is without influence on the value of the decision threshold on net counting value. $L D_{[B q]}$, in this case of figure, can be given by taking again the problem starting from the distribution of possible nets counting values for a whole of sources associated with each efficiencies, such as the average $\overline{\mathcal{A}}$ activities of the sources and the average $\bar{\varepsilon}$ efficiencies make it possible to write $\overline{N e t}=\bar{\varepsilon} \times \overline{\mathcal{A}} \times T$.

The value in detection limit corresponds to the true average activity such as $L D_{[B q]}=\bar{A} \Rightarrow L D_{[N e t]}=\bar{\varepsilon} \times L D_{[B q]} \times T$.

By assimilating the value of $L D_{[N e t]}$ to a net counting true mean value $\mu_{L D}$, then the variability of the efficiency can be introduced by regarding the distribution of counting possible Net as being generated by a law of Poisson of true average variable:

$$
\mu_{\varepsilon}=\frac{\varepsilon}{\bar{\varepsilon}} \times L D_{[N e t]}
$$

The law of distribution of this variable is written then $P(N)=\int_{\varepsilon} \frac{e^{\mu_{\varepsilon}} \times \mu_{\varepsilon}^{N}}{N !} \times f(\varepsilon) \times d \varepsilon$. 
The calculation of the standard deviation can be done by regarding this variable as the product of 2 variables: $[N e t]=\left[\begin{array}{c}\varepsilon \\ \bar{\varepsilon}\end{array}\right] \times\left[L D_{[N e t]}\right]$ with:

- $\left[\frac{\varepsilon}{\bar{\varepsilon}}\right]$ the variable reduced on the efficiencies of average 1 and standard deviation equal to the relative standard deviation $\sigma_{\left[\frac{\varepsilon}{\bar{\varepsilon}}\right]}=\sigma \% \%_{\varepsilon}$

- $\left[L D_{[N e t]}\right]$ a Poisson variable of average and variance LD.

The law of composition of uncertainties makes it possible to write for a product of two variables independent and by neglecting the cross derivative of second order:

$[Y]=\left[X_{1}\right] \times\left[X_{2}\right]$

$\sigma_{Y}^{2}\left(\bar{X}_{1}, \bar{X}_{2}\right) \approx\left(\bar{X}_{1}\right)^{2} \times \sigma_{X_{2}}^{2}+\left(\bar{X}_{2}\right)^{2} \times \sigma_{X_{1}}^{2}$

For the variables defined as previously one obtains:

$\sigma_{\mathrm{Net}} \approx \sqrt{\left(L D_{[\mathrm{Net}]} \times \sigma \% o_{\varepsilon}\right)^{2}+L D_{[\mathrm{Net}]}}$

By reintroducing the uncertainty brought back by the net background signal one obtains:

$$
\begin{aligned}
\boldsymbol{\sigma}_{N e T} & =\sqrt{L D_{[N \varepsilon T]}+\left(L D_{[N \varepsilon T]} \cdot \sigma \% o_{\varepsilon}\right)^{2}+\left(1+\frac{1}{n}\right)\left(\frac{B k G_{0}+1}{n}\right)} \\
& =\sqrt{L D_{[N \varepsilon T]}+\left(L D_{[N \varepsilon T]} \cdot \sigma \%\right)^{2}+\frac{L c_{[N \varepsilon T]}^{2}}{k_{l-\alpha}^{2}}} .
\end{aligned}
$$

By taking again the reasoning for the determination of the detection limit and by considering a law of Gaussian distribution of the efficiencies

$$
\begin{aligned}
& L D_{[\mathrm{Net}]}=L c_{[\mathrm{Net}]}+k_{1-\beta} \times \sqrt{L D_{[\mathrm{Net}]}+L D_{[\mathrm{Net}]}{ }^{2} \times \sigma^{o} o_{\varepsilon}{ }^{2}+\frac{L c_{[\mathrm{Net}]}{ }^{2}}{k_{1-\alpha}^{2}}} \\
& \left(L D_{[\mathrm{Net}]}-L c_{[\mathrm{Net}]}\right)^{2}=k_{1-\beta}^{2} \times\left(L D_{[\mathrm{Net}]}+L D_{[\mathrm{Net}]}{ }^{2} \times \sigma^{o}{ }^{2}+\frac{L c_{[\mathrm{Net}]}}{k_{1-\alpha}^{2}}\right) .
\end{aligned}
$$


The solution of this quadratic equation gives us:

$L D_{[\mathrm{Net}]}=\frac{\left(2 \times L c_{[\mathrm{Net}]}+k_{1-\beta}^{2}+\sqrt{\left[2 \times L c_{[N e t]}+k_{1-\beta}^{2}\right]^{2}-4 \times\left(1-k_{1-\beta}^{2} \times\left(\sigma \%_{\varepsilon}\right)^{2}\right) \times\left[1-\frac{k_{1-\beta}^{2}}{k_{1-\alpha}^{2}}\right] \times L c_{[\mathrm{Net}]}^{2}}\right)}{2 \times\left(1-k_{1-\beta}^{2} \times\left(\sigma \%_{\varepsilon}\right)^{2}\right)}$.

By taking risks a and $b$ rather symmetrical one can write (the second term under the root remains negligible in general)

$L D_{[\mathrm{Net}]} \approx \frac{k_{1-\alpha}^{2}+2 \times L c_{[\mathrm{Net}]}}{1-k_{1-\beta}^{2} \times\left(\sigma_{\varepsilon}\right)^{2}}$.

This expression is similar to the expression of the detection limit in the standard ISO 11929 (ISO, 2009, Eq. (28)).

\section{Appendix C: glossary}

Main formulas used in decision threshold accumulation.

\begin{tabular}{|c|c|c|c|}
\hline Experimental context & $\begin{array}{l}\text { Measurand of } \\
\text { interest }\end{array}$ & Associated threshold of decision & Limit of associated detection \\
\hline $\begin{array}{l}\text { single counting with } \\
r=\frac{T_{0}}{T_{S}}\end{array}$ & Net $=$ Gross $-\frac{B k G}{r}$ & $L c_{N e t}=k_{1-\alpha} \sqrt{\left(1+\frac{1}{r}\right) \cdot \frac{B k G+1}{r}}$ & $L D_{N e t}=k_{1-\beta}^{2}+2 L c_{N e t}$ \\
\hline $\begin{array}{l}\text { single activity } \\
\text { Measurement }\end{array}$ & $\mathcal{A}=\frac{N e t}{\varepsilon_{i} \cdot \gamma_{i} \cdot t}$ & $=\frac{L c_{\text {Net } i}}{\varepsilon_{i} \cdot \gamma_{i} \cdot t}$ & $L D_{\mathcal{A} i}=\frac{k_{1-\beta}^{2}+2 L c_{N e t}}{\varepsilon_{i} \cdot \gamma_{i} \cdot t}$ \\
\hline $\begin{array}{l}\text { Accumulation by } \\
\text { summation of the } \\
\text { counting values } \\
\text { (case No. 1) }\end{array}$ & $N e t_{\Sigma}=\sum_{i=1}^{n} N e t_{i}$ & $L c_{\Sigma N e t}=$ & $L D_{\Sigma N e t} \approx$ \\
\hline $\begin{array}{l}\text { Accumulation by } \\
\text { average of the } \\
\text { counting values }\end{array}$ & $\overline{N e t}_{n}=\frac{\sum_{i=1}^{n} N e t_{i}}{n}$ & $L c_{\overline{N e t_{n}}}=\frac{1}{n}$ & $L D_{\overline{N e_{n}}} \approx \frac{1}{n} \sqrt{2}$ \\
\hline $\begin{array}{l}\text { Accumulation by } \\
\text { summation of the } \\
\text { measured activities }\end{array}$ & $\hat{\mathcal{A}}_{\Sigma}=\sum_{i=1}^{n} \hat{\mathcal{A}}_{i}$ & $L c\left(\sum_{i=1}^{n} \hat{\mathcal{A}}_{i .}\right)=\sqrt{\sum_{i=1}^{n} L c_{\mathcal{A} i}^{2}}$ & $L D\left(\sum_{i=1}^{n} \hat{\mathcal{A}}_{i .}\right)=\sqrt{\sum_{i=1}^{n} L D_{\mathcal{A} i}^{2}}$ \\
\hline $\begin{array}{l}\text { Accumulation by } \\
\text { weighted average of } \\
\text { the measured } \\
\text { activities } \\
\text { (case No. 2) }\end{array}$ & $\hat{\mathcal{A}}_{\text {weigh. }}=\frac{\sum_{i=1}^{n} \frac{1}{u_{i}^{2}} \mathcal{A}_{i}}{\sum_{i=1}^{n} \frac{1}{u_{i}^{2}}}$ & $L c\left(\hat{\mathcal{A}}_{\text {weigh. }}\right)=\sqrt{\frac{1}{\sum_{i=1}^{n} \frac{1}{L c_{\mathcal{A}}^{2}}}}$ & $L D\left(\hat{\mathcal{A}}_{\text {weigh. }}\right) \approx \sqrt{\frac{1}{\sum_{i=1}^{n} \frac{1}{L D_{\mathcal{A} i}^{2}}}}$ \\
\hline $\begin{array}{l}\text { Accumulation by } \\
\text { weighted average of } \\
\text { the measured } \\
\text { activities with } \\
\text { variations in the } \\
\text { detection efficiency }\end{array}$ & $\hat{\mathcal{A}}_{\text {weigh. }}=\frac{\sum_{i=1}^{n} \frac{1}{u_{i}^{2}} \mathcal{A}_{i}}{\sum_{i=1}^{n} \frac{1}{u_{i}^{2}}}$ & $L c\left(\hat{\mathcal{A}}_{\text {weigh. }}\right)=\sqrt{\frac{1}{\sum_{i=1}^{n} \frac{1}{L c_{\mathcal{A} i}^{2}}}}$ & $\begin{array}{c}L D\left(\hat{\mathcal{A}}_{\text {weigh. }}\right) \approx C \cdot \sqrt{\frac{1}{\sum_{i=1}^{n} \frac{1}{L D_{\mathcal{A} i}^{2}}}} \\
C=\frac{1}{1-k_{1-\beta}^{2} \cdot \sigma_{\text {rel. }}^{2}}\end{array}$ \\
\hline
\end{tabular}


DECISION THRESHOLD ASSOCIATED WITH MULTIPLE MEASUREMENTS

\section{REFERENCES}

AMC (2001) What should be done with results below the detection limit? Mentioning the unmentionable. Analytical methods committee technical brief No. 5, April 2001. Royal Society of Chemistry, London, 2001, two unnumbered pages.

ISO 11929 (2009) Determination of the characteristic limits (decision threshold, detection limit and limit of the confidence interval) for measurements of ionizing radiations.

Fiévet B., Della Vedova C. (2010) Dealing with non-detect values in time-series measurements of radionuclide concentration in the marine environment, J. Environ. Radioact. 101 (1),1-7.

Helsel D.R. (2005) Nondetects and Data Analysis: Statistics for Censored Environmental Data. John Wiley and Sons, New York, p. 250.

MARLAP, Multi-Agency radiological laboratory Analytical protocols manual (2004) Vol. III EPA 402-B-04-001C, chapter 20, US Environmental Protection Agency

Vivier A., Aupiais J. (2007) Optimization of the decision threshold for single radioactive counting, $J$. Radiochim. Acta 95, 477-492.

Vivier A., Fottorino R., Rousse B. (2010) Seuil de décision et limite de détection : estimation interprétation et optimisation, ${ }^{\text {ère }}$ partie : principes de bases, Radioprotection 45, 321-343. 